\title{
Tersiyer Bir Merkezde Doğum Yapan Adolesan, Reprodüktif ve İleri Yaş Gebelerde Obstetrik ve Neonatal Sonuçların Karşılaş̦tırılması
}

\author{
Comparison of Obstetric and Neonatal Outcomes in Adolescent, Reproductive and
}

Old Age Pregnancies Delivery in a Tertiary Center

\author{
Sibel SAK ${ }^{1}$, Adnan İNCEBIYIK ${ }^{1}$, Hacer UYANIKOĞLU ${ }^{1}$, Ahmet Berkız TURP ${ }^{1}$ \\ Neşe Gül HILLALI I ${ }^{1}$, M. Erdal SAK ${ }^{1}$
}

1. Harran Üniversitesi, Kadın Hastalıkları ve Doğum Kliniği, Şanlıurfa

\section{$\ddot{O Z E T}$}

Amaç: Tersiyer bir merkezde doğum yapan adolesan, reprodüktif ve ileri yaş gebelerde obstetrik ve neonatal sonuçların karșılaștırılmast.

Materyal ve Metod: Harran Üniversitesi Tip Fakültesi Kadın Doğum Bölümünde 01.08.2015 -01.08.2016 yillarl arasında doğum yapmış olan adolesan yaş (14-18), reprodüktif yaş (19-38) ve ileri yaş (39-50) gebelerden toplam 126 hastanın dosyast retrospektif olarak incelendi. Maternal demografik veriler, gebelik komplikasyonları (Preterm doğum, prezentasyon anomalisi, intrauterin büyüme kısitlılı̆̆ (IUGR), preeklampsi, gestasyonel diabet (GDM), plesantal anomali, hospitalizasyon süresi, oligohidramnios, doğum şekli ve fetal sonuçlar (doğum ăgırliğl, apgar skorlarl, makrozomi konjenital malformasyonlar, inutero mort fetüs (IUMF) değerlendirildi.

Bulgular: Büyük çoğunluğu nulliparlardan oluşan adolesanlarda preterm eylem, doğum ă̆ırliğı, IUGR ,amniyon sivi anomalisi (oligo), gestasyonel diabet ve preeklampsi oranı reprodüktif ve ileri yaş gebelerle benzer çıkarken doğumdaki gestasyonel hafta anlamlı olarak küçük, fetal anomali sıkliğ anlamlı olarak yüksek bulundu. Illeri yaş gebelerde ise sezaryen oranlarl, plasenta previa totalis ve plasenta invazyon anomalisi görülme slklığl ve hospitalizasyon süresi anlaml yüksek saptandr. Reprodüktif grupta ise normal spontan doğum oranlar her iki gruba göre anlaml yüksek bulundu.

Sonuç: Bu çalışmada adolesan ve ileri yaş annelerin kendi yaş grublarına özgün çesitli risklerin bulunduğu gösterilmiştir. Bu yaş grubu gebelerde maternal ve neonatal olasi en iyi sonuca varabilmek için öncelikle bu gebelerin maternal ve fetal riskler ile ilgili bilgilendirilmesi, düzenli prenatal takip ve tedavi olmalarının sağlanması ve sosyal destek gerekmektedir.

Anahtar Kelimeler: adolesan; ileri yaş; obstetrik; neonatal

Iletişim Bilgileri

Sorumlu Yazar: Sibel SAK

Yazışma Adresi: Harran Üniversitesi, Kadın Hastalıkları ve Doğum Kliniği, Şanlıurfa

E-posta: drsibelsak@gmail.com

Tel: +90 (414) 3183000

Makale Geliş Tarihi: 26.03.2017

Makale Kabul Tarihi: 06.05.2017

DOI: http://dx.doi.org/10.16948/zktipb.300736

\section{ABSTRACT}

Objective: In this study, we aimed to evulate obstetric neonatal outcomes of adolescent and old age pregnants who gave birth in our center.

Material and Methods: A total of 126 pregnant women which were consist of adolascent (14-18), reproductive (19-38) and advanced (39-50) maternal age pregnancies and gave birth in Harran University of Medicine Faculty of Obstetric and Gynecology Department were compared retrospectively. Maternal demographic datas, obstetric complications (preterm delivery, abnormalities of presantation, intrauterin growth restriction (IUGR), preeclampsia, gestational diabetes mellitus (GDM), abnormalities of placentia, duration of hospitalization, oligohidramnios, type of delivery, fetal outcomes (birth weights of infants, apgar scores, macrosomia, congenital malformations, iumf) were evulated.

Results: Although the rates of birth weight infant, preterm labour, IUGR, amnion fluid abnormalities, GDM, macrosomia and preeclampsia were found similiar in adolescents of whom majority are nulliparous and reproductive, advanced maternal age women, the rates of gestational week at birth were found to be lower and frequency of congenital anomalies and abnormalities of presantation was found to be higher than the other both groups. The rate of sectio, placenta previa totalis and placenta invasion abnormalities, duration of hospitalization were higher significantly in advanced age maternal women. The normal spontaneous vaginal deliveries rate was significantly higher in reproductive group than the other groups.

Conclusion: This study has shown that the adolescent and advanced maternal age women have some kind of charecteristic high risks in respect to their age groups. For having the best maternal and neonatal outcomes in both groups, these women should be informed about maternal and fetal risks and provided regular perinatal follow ups and treatment. Also social support is needed.

Keywords: adolescent; advanced age; obstetric; neonatal 


\section{GİRİŞ}

Adolesan dönem çocukluktan erişkinliğe geçiş olan kişide biyolojik, sosyal ve psikolojik gelişim ve değişimlerin olduğu 10-19 yaş aral1ğındaki zaman dilimidir (1).

Adolesan gebelikte, bu yaşlardaki kızların gebeliğidir. Adolesan gebelik başta gelişmekte olan ülkeler olmak üzere gelișmiş ülkelerinde sorunudur. Gelişmiş ülkelerde evlilik öncesi cinsel birliktelik ve sonrasında oluşan planlı yada plansız gebelikler daha sık görülürken Türkiye gibi gelişmekte olan ülkelerde kültürel yap1 ve geleneklerden dolayı aynı zamanda düşük gelir ve eğitim seviyesine bağlı olarak erken yaş evlilikleri sıkça görülmektedir (2-4).

Adolesan gebelerde, preterm eylem, düşük doğum ağırlıklı infant, intrauterin gelişme geriliği, preeklampsi ve perinatal morbidite ve mortalite de artış gözlenmektedir (5).

Son 3 dekadda, çocuk doğurma yaşı reprodüktif tekniklerin ilerlemesinden ve sıkça kullanılmasından, kadınların çalışma hayatında daha çok yer alması, kariyer endişesi, genç yaşta yetersiz ekonomik bütçe, esnek olmayan çalışma saatleri, bakıc1 sıkıntısı gibi nedenlerden dolay1 38 yaş ve üzerine kaymıştır $(6,7)$.

İleri yaş gebeliklerinde de hipertansiyon, diabet, operatif müdahaleler, artmış fetal anomali insidans1 gibi riskler mevcuttur.

Çalıșmamızda, Türkiyenin doğusunda bulunan eğitim ve sosyoekonomik açıdan geri olan Türkiye'nin en yüksek doğurganlık ve kaba doğum hızına sahip olan Şanlıurfa ilinde, tersiyer bir merkez olarak adolesan, reproduktif ve ileri yaş gebeliklerin perinatal ve obstetrik sonuçlarını karşılaştırmayı hedefledik.

\section{MATERYAL ve METOD}

Çalışmamızdaki veriler 01.08.201501.08.2016 y1lları arasında bölgenin en riskli obstetrik hastalarını kabul eden ve III. düzey obstetrik yoğun bakım hizmeti veren Harran Üniversitesi Tıp Fakültesi Kadın Hastalıkları ve Doğum Bölümünde doğum yapmış gebelerden toplam 126 tanesinin dosyasından yaş gruplarına göre rastgele seçilerek analiz edildi. 126 hastadan 26's1 (\%20.63) adolesan, 50'si (\%39.68) reprodüktif ve 50'si (\%39.68) ileri yaş gebelerdi. 14-18 yaş arasındaki gebeler adolesan gebe, 39 yaş ve üzeri gebeler ileri yaş gebe olarak değerlendirildi. Kontrol grubu olarak 19-38 yaş arasındaki reprodüktif yaş gebelikleri çalışmaya alındı.
$\mathrm{Bu}$ grupların demografik özellikleri, maternal klinik sonuçlar ve prenatal sonuçlar karşılaştırıldı. Anne ile ilgili olarak, yaş, gravide, gebelik komplikasyonları (Preterm doğum, ablasyo plasenta, preeklampsi, GDM, plasental anomali, hospitalizasyon süresi, oligohidramnios), doğum şekli ve fetal sonuçlar (Apgar skorları, IUGR, makrozomi, konjenital malformasyonlar) değerlendirildi. Doğum ağırlığı 2500 gr altında olanlar düşük doğum ağırlıklı olarak kabul edildi. 1.dakika apgar skoru 4'ün altı, 5.dakika apgar skoru 7'nin altı düşük apgar skoru kabul edildi. Gestasyonel gebelik haftas1 son adet tarihine, ilk usg ye bazende her ikisine bakılarak tespit edildi. 37 hafta öncesi doğumlar erken doğum kabul edildi. Sürekli değişkenler ortalama \pm standart sapma veya ortanca (minimum-maksimum) şeklinde, nominal değișkenler ise olgu sayıs1 ve \% olarak gösterildi. Gruplar arasında ortalamalar yönünden farkin önemliliği Student's t testi ile ortanca değerler yönünden, gruplar arasında anlamlı farkın olup olmadığı ise Mann Whitney U testi ile araştırildı. Nominal değişkenler ki-kare testi ile değerlendirildi. $\mathrm{P}<0.05$ için sonuçlar istatistiksel olarak anlamlı kabul edildi. Bu üç grubun ortalama değerleri ANOVA testi ile analiz edildi, sonrasında multiple karşılaştırmalar için BONFERRONI post-hoc testi kullanild1 ve istatistiksel analizler için "IBM SPSS STATISTICS versiyon 20" programı kullanıldı.

\section{BULGULAR}

Adolesan yaş grubu gebelerin yaş ortalaması $17.12 \pm 1.07(14-18)$, ileri yaş grubu gebelerin yaş ortalamas1 41.46 $\pm 2.16(39-50)$ kontrol grubunun yaş ortalaması 28.88 $\pm 6.02(19-38)$, olarak saptand1. Adolesan yaş gebelerin büyük çoğunluğu nullipar (1-3) iken ileri yaş gebelerin tamamı multipar (2-14) idi. Gravida açısından değerlendirildiğinde en yüksek değer ileri yaş grubunda olduğu gözlendi. Üç grup arasında anlamlı farklılık tespit edildi $(\mathrm{p}<0.001)$.

Doğumdaki gestasyonel yaş adolesanlarda reprodüktif ve ileri yaş gebelere göre anlamlı olarak daha küçük bulunurken preterm eylem açısindan gruplar arasinda sonuçlar benzer bulundu $(p=0.006$ ve $p<0.068$ sirasiyla). Doğum ağırlığ en düşük kiloya sahip grup adolesan gebeler olmasına rağmen bu fark istatistiksel açıdan anlam11 izlenmedi $(p=0.066)$ Normal doğum oranının reprodüktif grupta adolessan ve ileri yaş ile kıyaslandığında istatistiksel açıdan daha yüksek olduğu gözlendi ( $p=0.002, p<0.001$, sirasiyla).

Hospitalizasyon süresi en uzun ileri yaş grubu gebelerde izlendi. Adolesan ve reprudüktif yaş grubu gebelerde adolesan yaş gebelerin büyük 
çoğunluğu nullipar (1-3) iken ileri yaș gebelerin tamamı multipar (2-14) idi. 1.ve 5.Apgar skorları açısından gruplar arasında anlamlı bir farklıl1k saptanmadi $(p=0.077, p=0.087) .126$ gebenin sadece üçünde IUGR saptandı. Ancak gruplar arasında anlamlı bir fark bulunmadı $(\mathrm{p}=0.638)$. Adolesan grupta yer alan iki gebenin bebeğinde konjenital anomali olarak hidrosefali saptanırken, diğer iki grupta anomalili bebeğe rastlanılmadı.

Plasenta previa totalis en fazla $11(\% 22)$ olgu ile ileri yaş grubunda izlendi $(\mathrm{p}=0.017)$. Adolesan ve reprodüktif yas grupları arasında ise fark tespit edilmedi $(\mathrm{p}=0.690)$. Plasenta invazyon anomalisi en fazla ileri yaş grubunda gözlendi (Tablo 2). Her üç grupta en sik baş prezantasyonun görülmesiyle birlikte prezentasyon anomalisi adolesan grupta diğer iki gruba kıyasla daha fazla olduğu görüldü (Tablo 2). Preeklampsi en sik (\%19.2) adolesan ve ileri yaş (\%18) gebelerde görülürken reprodüktif yaş gebelerle aralarında anlamlı bir istatistik fark izlenmedi $(\mathrm{p}=0.260)$. Gestasyonel diabet, makrozomi ve oligo açısından gruplar arasında fark tespit edilmedi (Tablo 2).

\section{TARTIŞMA}

Adolesan ve ileri yaş gebelikler özellikle gelişmekte olan ülkelerin sorunu olmakla birlikte Türkiye istatistik kurumu 2016 raporuna göre Türkiye'nin en yüksek doğurganlık hızı (4.38) ve kaba doğum hızına (33.3) sahip olan Şanlıurfa'da düşük sosyoekonomik durum, düşük eğitim seviyesi ve kültürel geleneksel nedenlerden dolayı daha sık görülmektedir.

Ülkemizde ve dünya genelinde adolesanlarda düşük doğum ağırlığı $(8,9)$, premature doğum (9-12) ve perinatal morbidite ve mortalitede artıs (13) gibi kötü perinatal sonuçların olduğunu dökümente eden bir çok çalışma olmasına rağmen bu konuda konsensus yoktur (14-17). Çoğu literatürde belirtildiğinin aksine araştırmamızda adolesan grupta preterm eylem doğumları ileri yaş ve reprodüktif yaş grubuna göre anlamlı yüksek tespit edemedik. Sadece doğum sırasındaki gebelik haftasını adolesanlarda diğer iki gruba göre anlamlı düşük tespit ettik. Lao ve arkadaşları (5) adolesan yaş gebeliklerde daha yüksek preterm eylem riski ve düşük doğum ağırlıklı bebek doğurma riski olduğunu ve yüksek sezaryen oranları bulunduğunu, Raatikainen ve ark. (20) ise tam tersine adolasanlarda artmış preterm eylem riskinin ve düşük doğum ağırlıklı bebek doğurma riskinin olmadığını belirtmişlerdir. Guimaraes ve ark. (18) 4746 adolesan gebe ile yaptıkları çalışmalarında düşük doğum ağırlığı riskini yetersiz antenatal bakıma ve adolasanlaın partnersiz yaşamalarına bağlamışlardır. Scholl ve ark. (19) erken maternal yaşın gebelik sonuçlarına etkilerini araştırdıkları çalışmalarında kronolojik yaşın gebelik sonuçlarını tahmin etmede iyi bir belirteç olmadığını, adölesanlarda artmış riskin biyolojik immatürite, yetersiz antenatal bakım, gebelik öncesi düșük maternal kilo gibi nedenlere bağlı olduğunu belirtmişlerdir. Çalışmamızda adolesan, reprodüktif ve ileri yaş gebelerde doğum ağırlığı açısından anlamlı bir fark bulamadık. Bunun sebebi bölgemizdeki adolasan gebelerin tümümün evli olması ve partnerlerinin olması, istenilen gebelikler olması nedeniyle antenatal bakımın düzenli ve yeterli olması, bölgemizdeki adolesan grubun belki daha doğal beslenmeye veya kalitsal nedenlere bağlı olarak gebelik öncesi kilolarının yeterli olması düşünülebilir.

Literatürdeki birtakım yayınlara göre adolesanda sezaryen insidansının henüz erişkin yapıya ulaşmamış immatür pelvis nedeniyle arttığı bir takım yayınlarda da ileri yaş gebeliklere göre sezaryen insidansının daha düşük olduğu bildirilmiştir $(16,21-23)$. Çalışmamızda ileri yaş gebelerde sezaryen oranlarını, reprodüktif grupta da normal spontan vajinal doğumları diğer iki gruba göre anlamlı yüksek bulduk. Çalışmaya dahil ettiğimiz adolesanlarında sezaryen oranı $\% 61.5$ normal doğum oranı \%38.5 idi. Illeri yaş ve adolasan yaş gebelerde sezaryen oranın yüksek olması bölgede tersiyer ve yüksek riskli obstetrik hastalar için refarans merkezi olmamız aynı zamanda ileri

Tablo 1: Maternal demografik özellikler, antenatal prenatal sonuçlar.

\begin{tabular}{|c|c|c|c|c|}
\hline & $\begin{array}{l}\text { Adolasan yaş gebeler } \\
\qquad(n=26)\end{array}$ & $\begin{array}{l}\text { Reprodüktif yaş gebeler } \\
\qquad(n=50)\end{array}$ & $\begin{array}{l}\text { İleri yaş gebeler } \\
\qquad(n=50)\end{array}$ & $\mathbf{p}$ \\
\hline Yaş & $17.12 \pm 1.07$ & $28.88 \pm 6.02$ & $41.46 \pm 2.16$ & $<0.001$ \\
\hline Gravida & $1.31 \pm 0.55$ & $4.06 \pm 2.79$ & $6.82 \pm 2.79$ & $<0.001$ \\
\hline Gestasyonel yaş & $34.85 \pm 4.62$ & $37.20 \pm 2.19$ & $36.58 \pm 2.68$ & 0.006 \\
\hline Doğum ağırlığı & $2490.76 \pm 855.91$ & $2880.62 \pm 570.90$ & $2819.00 \pm 739.46$ & 0.066 \\
\hline \multicolumn{5}{|l|}{ Doğum şekli } \\
\hline $\begin{array}{l}\text { Vajinal doğum } \\
\text { Sezaryen doğum }\end{array}$ & $\begin{array}{l}10(38.5 \%) \\
16(61.5 \%)\end{array}$ & $\begin{array}{l}37(74.0 \%) \\
13(26.0 \%)\end{array}$ & $\begin{array}{l}1(2.0 \%) \\
49(98.0 \%)\end{array}$ & $<0.001$ \\
\hline Hospitalizasyon süresi & $2.88 \pm 2.37$ & $1.84 \pm 1.27$ & $3.04 \pm 2.38$ & 0.009 \\
\hline Apgar 1 & $5.35 \pm 2.40$ & $6.38 \pm 2.03$ & $5.62 \pm 2.03$ & 0.077 \\
\hline Apgar 5 & $6.96 \pm 2.96$ & $8.10 \pm 2.26$ & $7.28 \pm 2.29$ & 0.087 \\
\hline
\end{tabular}


yaș annelerin tamamen multipar olup geçirilmiș sezaryen öyküsü endikasyonu ile opere edilmesi ile açıklanabilir.

Dietl ve ark. (24) yapmış oldukları çalıșmada sezaryen yada normal doğum olduğuna bakılmaksızın ileri yaş annelerde hastanede kalış süresinin genç annelere göre daha uzun olduğunu belirtmişlerdir. Klemetti (25) ve ark. ve Yogev ve ark. (26) çalışmalarında benzer sonuçlar bildirmişlerdir. Çalışmamızda hospitalizasyon süresi ileri yaş grubunda adolesan yaş grubuna göre daha uzun saptand1. En kısa hospitalizasyon süresi reprodüktif grupta izlendi. Bizde ileri yaş grubunda hospitalizasyon süresinin uzun olmasinı $\% 49^{\text {‘ unun }}$ sezaryen olmasina ve daha fazla komorbit hastalik bulunmasına bağladık. Her üç gurupta en sık baş prezantasyonu görüldüğü halde prezantasyon anomolisi adolesan grupta anlamlı yüksek izlendi.

\begin{tabular}{|c|c|c|c|c|}
\hline & Adolesan & $\begin{array}{l}\text { Repro- } \\
\text { düktif }\end{array}$ & İleri yaş & $\mathrm{p}$ \\
\hline \multicolumn{5}{|l|}{ Doğum zamanı $(\mathrm{n}, \%)$} \\
\hline Preterm & $10(38 \%)$ & $12(24 \%)$ & $23(46 \%)$ & 006 \\
\hline Term & $16(62 \%)$ & $38(76 \%)$ & $27(\% 54)$ & \\
\hline \multicolumn{5}{|l|}{ Doğum şekli $(n, \%)$} \\
\hline Vajinal doğum & $10(38.5 \%)$ & $37(74.0 \%)$ & $1(2.0 \%)$ & \\
\hline Sezaryen doğum & $16(61.5 \%)$ & $13(26.0 \%)$ & $49(98.0 \%)$ & 20.001 \\
\hline IUGR (n,\%) & $1(3.8 \%)$ & $2(4 \%)$ & 0 & 0.638 \\
\hline $\begin{array}{l}\text { Konjenital Anomali } \\
(\mathrm{n}, \%)\end{array}$ & $2(7.6 \%)$ & 0 & 0 & 0.020 \\
\hline \multicolumn{5}{|l|}{ Plasental anomali $(n, \%)$} \\
\hline Pl.Previa & $1(3.8 \%)$ & $3(6 \%)$ & $11(22 \%)$ & \\
\hline Pl.invasyon anomalisi & $0(0.0 \%)$ & $1(2 \%)$ & $7(14 \%)$ & \\
\hline $\begin{array}{l}\text { Gestasyonel Diabet } \\
(\mathrm{n}, \%)\end{array}$ & 0 & $2(2 \%)$ & $4(8 \%)$ & 0.156 \\
\hline Makrozomi(n,\%) & 0 & $1(2 \%)$ & $2(4 \%)$ & 0.541 \\
\hline Preeklampsi(n,\%) & $5 \% 19.2)$ & $4(8.0 \%)$ & $9(18 \%)$ & 0.260 \\
\hline $\begin{array}{l}\text { Oligohidramniyoz } \\
(n, \%)\end{array}$ & $4(15,4 \%)$ & $3(6,0 \%)$ & $6(12,0 \%)$ & 0.390 \\
\hline \multicolumn{5}{|l|}{ Prezentasyon $(n, \%)$} \\
\hline Baş & $18(69,2 \%)$ & $48(96 \%)$ & $46(92 \%)$ & \\
\hline Makat & $5(19,2 \%)$ & $2(4 \%)$ & 0 & 0.001 \\
\hline Transvers & $3(11,5 \%)$ & 0 & $4(8,0 \%)$ & \\
\hline
\end{tabular}

Preeklampsi bir çok çalışmada adolesan yaș gurubunda daha yüksek bulunurken $(8,29)$ birtakım çalışmalarda ileri yaş gurubunda daha yüksek $(24,27,28)$ bulunmuş, kimi çalışmalarda da guruplar arasında fark bulunamamıştır $(16,30)$. Bizde preeklampsi sıklığı açısından guruplar arasında anlamlı fark bulamadık. Her ne kadar adolesan $g$ urupta (\%19.2) daha çok görülsede preeklampsi için risk faktörlerinden biri olan grandmultiparite ileri yaş gebelerin çoğunda mevcut olduğundan aradaki farkı anlamsız kılmış olabilir.

Plasental yapışma anomalilerinden olan plasenta perkreata ve plasenta previa totalis ileri yaş grubunda adolesan yaş grubuna göre anlamlı yüksek bulundu. Adolesan gebelerde oldukça nadir olmasının sebebi adolesan gebelerin nerdeyse tamamının nullipar olması, kliniğimize gelen ve refere olan ileri yaş gebelerinde çoğunun mükerrer kez sezaryen olmalarından kaynaklanıyordu (31, 32).

126 gebeden sadece ikisinde fetal anomali saptand. Her iki anomali hidrosefali idi ve her ikiside adolesan gebe grubunda tespit edildi. Chantrapanichkul Pve ark. yaptıkları çalışmada yapısal konjenital anomalileri özellikle serabral sinir sistemi ile ilgili olanları adolesan grupta anlamlı yüksek bulmuşlar (32). Bazı çalışmalarda da fetal anomali sıklığı kontrol gurubunda adolesan gruba göre anlamlı yüksek bulunmuștur (33). Adolesan ve ileri yaş grubu arasında IUGR ve oligohidranmios açısından anlamlı fark bulunamadı. Seçkin ve ark. da çalışmalarında IUGR ve oligohidramnios sonuçlarını adolasan ve kontrol gurubunda benzer bulmuşlar (33).

Gestasyonel diabet gebelerde en s1k görülen metobolik komplikasyondur. Bir çok çalışma ileri yaş gebeliklerde gestasyonel diabet gelişme sıklığının daha yüksek olduğunu hatta tek başına yaşın gestasyonel diabet gelişimi için bağımsız bir risk faktörü olduğunu belirtmişlerdir $(24,26$, 31). Çalışmamızda gestasyonel diabet riskini ileri yaş grubunda daha fazla olduğunu tesbit etsekte gruplar arasında anlamlı fark bulamadik. Makrazomik fetus sıklığınında ileri yaşta artmış olması gestasyonel diabet gibi anne yaşının artması ile birlikte makrozomik bebek doğurma olasıllı̆ının artmasından kaynaklanmaktadır (33).

Gestasyonel diabet gibi ileri yaş gurubunda makrozomiyi daha sık görsekte guruplar arasında anlaml fark izlenmedi. Kliniğimize 1 yıl içinde başvuran toplam 26 adolesan gebenin sayısının düșük olması eğitim sevyesi ve bilinç düzeyinin, sosyal medya ve sağlık bakanlığının belirlediği politikalar nedeni ile artmasına bağlı düşünülmektedir. Adolesan gebe sayısının daha fazla olduğu adolesan, ileri yaş ve reprodüktif yaş gebelerde 
obstetrik ve neonatal sonuçların değerlendirildiği çalışmalar da litaratüre daha kapsamlı katkı sağlıyacaktır.

Sonuç olarak, düşük soyoekonomik ve eğitim düzeyi adolasan gebelik oranını artırırken aynı zamanda kırsal bölgelerde çocuk sayısının kadınlığın ve gücün göstergesi olarak düşünülmesi dolayısı ile kadınların doğurganlıklarını devam ettirme isteği ileri yaș gebelerin oranını artırmaktadır. Sağlıklı toplumların oluşabilmesi için sağlıklı anne ve sağlıklı yenidoğanların gerekliliği sarttır. Bu nedenle sosyoekonomik ve eğitim düzeyinin yükseltilmesi, adolesanların güvenli sex ve kontrespsiyon hakkında bilgilendirilmesi özellikle kırsal bölgede yaşayan adolesan ve ileri yaş gebelere yaşlarına ilişkin matenal ve fetal risklerin anlatılması, prenatal takip ve tedavinin düzenli yapılmasının vurgulanması gerekmektedir.

\section{KAYNA KLAR}

1. World Health Organization (WHO): WHO guidelines on preventing early pregnancy and poor reproductive outcome among adolescents in developing countries. Geneva, WHO; 2011

2. Karabulut A, Ozkan S, Bozkurt AI, Karahan T, Kayan S. Perinatal outcomes and risk factors in adolescent and advanced age pregnancies: comparison with normal reproductive age women. J Obstet Gynaecol 2013;33:346-50

3. Kaplanoglu M, Kaplanoglu D, Usman MG. Postpartum contraception in adoles-cents: data from a single tertiary clinic in southeast of Turkey. Glob J Health Sci 2014;7:80

4. Allen J, Gamble J, Stapleton H, Kildea S. Does the way maternity care is provided affect maternal and neonatal outcomes for young women? A review of the research literature. Women Birth 2012;25:54-63

5. Lao T, Ho L. Obstetric outcome of teenage pregnancies. Hum Reprod. 1998;13:3228-3232

6. Heino A, Gissler M. The statistics on assisted fertility treat ments. Helsinki:THL 2012 (The National Institute for Health andWelfare

7. Bertram H, Bujard M, Rösler W. Rush-hour des Lebens: Geburtenaufschub, Einkommensverläufe und familienpolitische Perspektiven. Journal für Reproduktionsmedizin und Endokrinologie 2011; 8: 91-99

8. Hoekelman RA. Teenage pregnancy--one of our nation's most challenging dilemmas. Pediatr Ann. 1993;22(2):81-2.

9. Amini SB, Catalano PM, Dierker LJ, Mann LI. Births to teenagers: trends and obstetric outcomes. Obstet Gynecol. 1996;87(5 Pt1):668-74

10. Miller FC. Impact of adolescent pregnancy as we approach the new millennium. J Pediatr Adolesc Gynecol. 2000;13(1):5-8

11. Yoder BA, Young MK. Neonatal outcomes of teenage pregnancy in a military population. Obstet Gynecol. 1997;90:500-6

12. English PB, Kharrazi M, Guendelman S. Pregnancy outcomes and risk factors in Mexican Americans: the effect of language use and mother's birthplace. Ethn Dis. 1997;7(3):229-40

13. Williams RL, Binkin NJ, Clingman EJ. Pregnancy outcomes among Spanish-surname women in California. Am J Public Health. 1986;76(4):387-91

14. Yildirim Y, Inal MM, Tinar S. Reproductive and obstetric characteristics of adolescen pregnancies in Turkish women. $J$ Pediatr Adolesc Gynecol 2005;18:249-253
15. Melekoğlu R, Evrüke C, Kafadar T, Misirloğ̆lu S, Büyükkurt $S$, Ozgünen FT. Perinatal Outcomes of Adolescent Pregnancy Türk Jinekoloji ve Obstetrik Derneği Dergisi 2013;10:213-9

16. Azevedo WF, Diniz MB, Fonseca ES, Azevedo LM, Evangelista $C B$. Complications in adolescent pregnancy: systematic review of the literature. Einstein (Sao Paulo). 2015;9:0

17. Jeha D, Usta I, Ghulmiyyah L, Nassar A. A review of the risks and consequences of adolescent pregnancy. J Neonatal Perinatal Med. 2015;12

18. Guimarães AM, Bettiol H, SouzaLd, Gurgel RO, Almeida ML, Ribeiro ER, Goldaniv MZ, Barbieri MA. Is adolescent pregnancy a risk factor for low birth weight? Rev Saude Publica. 2013;47:11-9

19. Scholl TO, Hediger ML, Huang J, Johnson FE, Smith W, Ances IG. Young maternal age and parity. Influences on pregnancy outcome. Ann Epidemiol 1992;2:565-75

20. Raatikainen K, Heiskanen N, Verkasalo P, Heinonen S. Good outcome of teenage pregnancies in high-quality maternity care. Eur J Public Health. 2006;16:157-161

21. Zeteroğlu S, Şahin I, Gol K. Cesarean delivery rates in adolescent pregnancy. Eur J Contracept Reprod Health Care. 2005; 10:119-22

22. Chandra PC, Schiavello HJ, Ravi B et al. Pregnancy outcomes in urban teenagers. Int $J$ Gynaecol Obstet 2002;79(2):117-22

23. Khwaja SS, Al-Sibai MH, Al-Suleiman SA et al. Obs $\neg$ tetric implications of pregnancy in adolescence. Acta Obstet Gynecol Scand 1986;65(1):57-61

24. Dietl A, Cupisti S,. Beckmann M. W. Schwab M, Zollner U. Pregnancy and Obstetrical Outcomes inWomen Over 40 Years of Age Geburtsh Frauenheilk 2015; 75: 827-832

25. Klemetti R, Gissler M, Sainio $S$ et al. Associations of maternal age with maternity care use and birth outcomes in primiparous women: a comparison of results in 1991 and 2008 in Finland. BJOG 2014; 121: 356-362

26. Yogev Y, Melamed N, Bardin R et al. Pregnancy outcome at extremely advanced maternal age. Am J Obstet Gynecol 2010; 203: 558.e1-558. e7

27. Salihu HM, Shumpert MN, Slay $M$ et al. Childbearing beyond maternal age 50 and fetal outcomes in the United States. Obstet Gynecol 2003; 102 (5 Pt 1): 1006-1014

28. Callaway LK, Lust K, McIntyre HD. Pregnancy outcomes in women of very advanced maternal age. Aust $N Z J$ Obstet Gynaecol 2005; 45:12

29. Stevens-Simon C, McAnarney ER. Adolescent pregnancy. Gestational weight gain and maternal and infant outcomes. Am J Dis Child. 1992 Nov;146(11):1359-64

30. Imır GA, Çetin M, Balta Ö, Büyükayhan D, Çetin A. Perinatal Outcomes of Adolescent Pregnancies at a University Hospital inTurkey. Journal of the Turkish-German Gynecological Association 2008;9:70-73

31. Cleary-Goldman J, Malone FD, Vidaver J, Ball RH, Nyberg DA, Comstock $C H$, et al. Impact of maternal age on obstetric outcome. Obstet Gynecol 2005;105(5 Pt 1): 983-90

32. Panicha Chantrapanichkul, Saifon Chawanpaiboon Adverse pregnancy outcomes in cases involving extremely young maternal age International Journal of Gynecology and Obstetrics 120 (2013) 160-164

33. Seçkin KD, Yücel B, Karslı MF, Özdemir C.. Adölesan Doğumların Demografik Özellikleri ve Maternal-Fetal Sonuçları: Istanbul'da Referans Bir Hastanede Gerçekleştirilen Olgu-Kontrol Çalıșması, Okmeydanı Tıp Dergisi 2016; 32(1):14-18 